
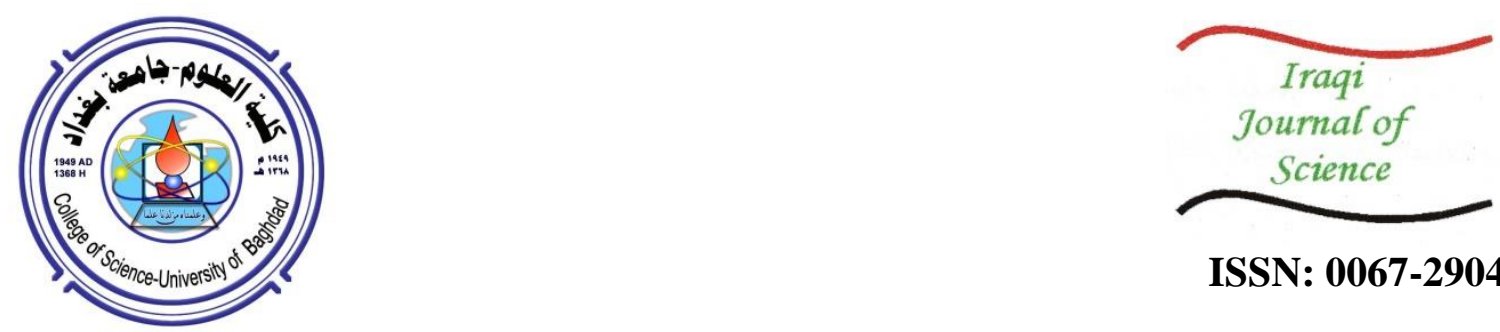

ISSN: 0067-2904

\title{
Analysis and Prediction of COVID-19 Outbreak by a Numerical Modelling
}

\author{
Dilshad Azad Mohammed ${ }^{1}$, Hassan Mohammad Tawfeeq ${ }^{2^{*}}$, Kameran Mohammed Ali $^{2}$ \\ ${ }^{1}$ Department of Refrigeration \& Air conditioning, Kalar Technical Institute, Sulaimani Polytechnic University, \\ Kalar, Kurdistan Region, Iraq \\ ${ }^{2}$ Department of Medical Lab Technology, Kalar Technical Institute, Sulaimani Polytechnic University, Kalar, \\ Kurdistan Region, Iraq \\ ${ }^{3}$ School of Life Sciences, University of Nottingham, NG7 2RD, UK \\ ${ }^{4}$ Department Of Biology, College of Education, University of Garmian, Kalar, Kurdistan region, Iraq
}

Received: 29/8/2020 Accepted: 11/11/2020

\begin{abstract}
Pandemic COVID-19 is a contagious disease affecting more than 200 countries, territories, and regions. Recently, Iraq is one of the countries that have immensely suffered from this outbreak. The Kurdistan Region of Iraq (KRI) is also prone to the disease. Until now, more than 23,000 confirmed cases have been recorded in the region. Since the onset of the COVID-19 in Wuhan, based on epidemiological modelling, researchers have used various models to predict the future of the epidemic and the time of peak, yielding diverse numbers in different countries. This study aims to estimate the basic reproductive number $\left[R_{0}\right]$ for COVID-19 in KRI, using the standard SIR (Susceptible-Infected-Removed) epidemic model. A system of nonlinear differential equations was formulated and solved numerically by the $4^{\text {th }}$ order Runge-Kutta method. The reproductive numbers $R_{0}$ was estimated by the method of fitting the curves between the actual daily data and numerical solution by applying the least square method. For the analysis, data were taken for the duration of 165 days, from $1^{\text {st }}$ of March to $12^{\text {th }}$ August 2020, in a population of 5.2 million. It is concluded that the $R_{0}$ value was fluctuating during the outbreak, with an average of 1.33 , predicting that infection cases will reach their maximum value of around 540,000 on the $5^{\text {th }}$ of November 2020. Then, the spread of the disease will die out since the number of susceptible people will decrease to about 3.2 million. While the number of removed individuals will reach approximately to 1.5 million.
\end{abstract}

Keywords: COVID-19, Numerical Model, $4^{\text {th }}$ order Runge-Kutta, SIR, Reproductive Number

$$
\begin{aligned}
& \text { تحليل وتنبؤ جائحة المرض COVID-19 بطربقة النمذجة العددية }
\end{aligned}
$$

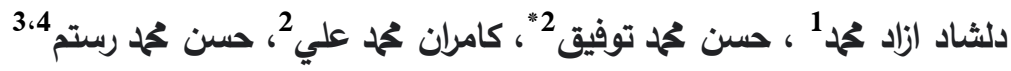

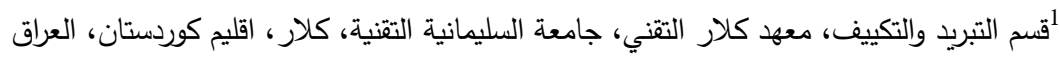

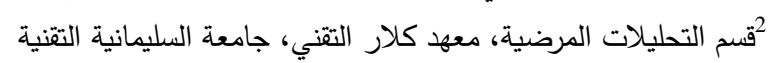

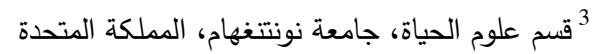

$$
\begin{aligned}
& \text { 4 قسم علوم الحياة، كلية التربية، جامعة كرميان، كلار ، اقليم كوردستان، العراق العيات }
\end{aligned}
$$

*Email: hassan.tawfeeq@spu.edu.iq 


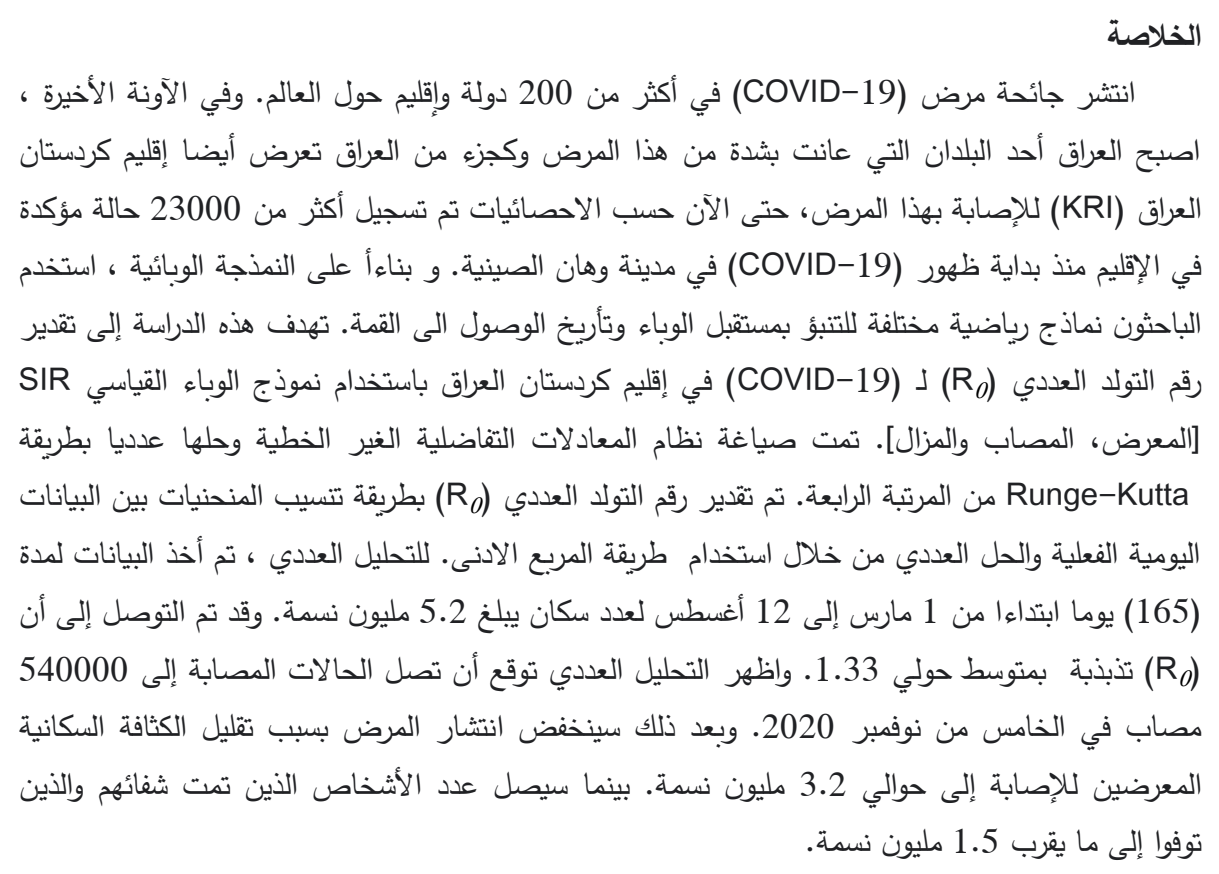

\section{Introduction}

The coronavirus disease 2019 (COVID-19) is a contagious disease which can be transmitted through droplets, aerosols, and direct contact [1-3]. It is caused by the severe acute respiratory syndrome coronavirus 2 (SARS-CoV-2), a novel coronavirus, which emerged in Wuhan during early December, 2019 [4, 5]. The symptoms of the infection include fever, cough, myalgia, fatigue, sputum production, headache, haemoptysis, diarrhoea, dyspnoea, and lymphopenia [6]. In more severe cases, COVID-19 can cause pneumonia and even death [7]. The incubation period is believed to extend to 14 days with a median time of approximately 5.2 days [8].

The COVID-19 has spread rapidly throughout the world as it has been found to have higher levels of transmissibility and pandemic risk than the SARS-CoV [9]. It has rapidly resulted in over 20 million confirmed cases and more than 750,000 deaths worldwide in less than 9 months [7]. Due to the sharp escalating level of spread on March 11, the World Health Organization (WHO) declared the COVID-19 outbreak as a global pandemic [10].

The epidemiological prediction based upon mathematical modelling plays a key role to understand the pathway of the epidemic and propose effective strategies in controlling the disease [11].

SIR is a commonly used model for the transmission of the disease from human to human [12]. SIR is considered to be one of the most reliable simple tools which consists of three compartments; susceptible, infected, and removed [11, 13, 14].

The basic reproduction number $\left[R_{0}\right]$ is a measure to evaluate the transmissibility of the virus in a particular population. Sustainability of the transmission of the disease depends on $R_{0}$ value; when $R_{0}>$ 1 , the disease is most likely developed to secondary cases. However, $R_{0} \leq 1$ indicates that the secondary cases in the outbreak are declining [15].

SIR model has been used in several studies to analyse the spread of COVID-19 [16-18]. The evaluation of COVID-19 by modelling in KRI has not been conducted to predict the behaviour of the disease spreading. Therefore, in this study, a numerical model for predicting the outbreak has been used to estimate how the quarantine, easy restriction, and population mixing affect outbreak progression. Accordingly, the model paves the way for the authority in charge to manage measuresrelated policies which can control and eradicate the infection.

\section{Materials and Methods}

In this study, a coupled system of nonlinear differential equations derived by Kermack and McKendrick in 1927 [19] is used. The system consists of three differential equations based on the classification which divides the population into three compartments; Susceptible $[S]$, Infected $[I]$ and Removed $[R]$, which is known as the SIR model, as shown in Figure 1. The interactions between the categories are controlled by a transmission rate $[\beta]$ and recovery rate $[\gamma]$. 


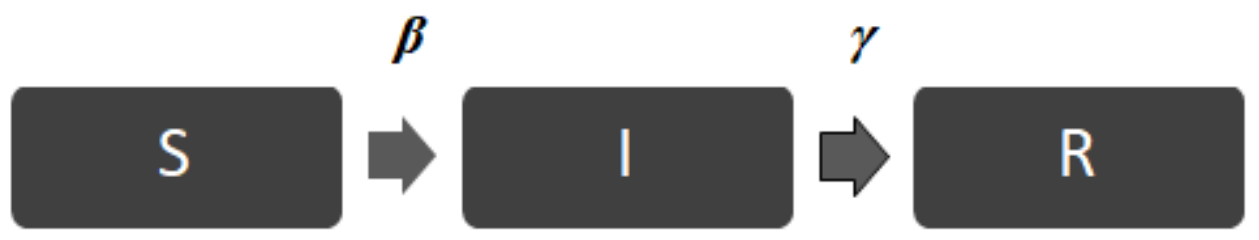

Figure 1-Schematic diagram of SIR Model; S, susceptible; I, infected; R, removed; $\beta$, transmission rate and $\gamma$, recovery rate.

The independent variable is time [t] measured in days and the dependent variables are $[S, I$ and $R]$. We consider three related sets of dependent variables. Equations 1,2 and 3 are related to the rate of change of susceptible population, the rate of change of infected population, and the rate of change of removed population, respectively.

$$
\begin{aligned}
& \frac{d S}{d t}=-\beta S(t) I(t) \\
& \frac{d I}{d t}=\beta S(t) I(t)-\gamma I(t) \\
& \frac{d R}{d t}=\gamma I(t) \\
& R_{o}=\frac{\beta}{\gamma}
\end{aligned}
$$

Equation 4 represents the reproductive number $\left[R_{0}\right]$, which is the key point to identify the epidemic occurrence and disease severity.

\section{Assumptions}

For simplifying the analysis, the following assumptions are made [20]:

1- The total population number $[\mathrm{N}]$ is constant, ignoring births, immigration, and natural death. Accordingly, the rate of change of $[\mathrm{N}]$ will be zero. This will lead to:

$$
N=S+I+R
$$

$$
\frac{d N}{d t}=\frac{d S}{d t}+\frac{d I}{d t}+\frac{d R}{d t}=0
$$

2- The population is homogeneously distributed.

3- Recovered individuals become immune and, hence, remain in the removed compartment.

4- The removed compartment also includes the individuals who died from the disease.

\section{Runge-Kutta $4^{\text {th }}$ order method}

The $4^{\text {th }}$ order Runge-Kutta method for a system of differential equations has the following forms [21]:

$$
\begin{aligned}
S_{i+1} & =S_{i}+\frac{1}{6}\left(K_{1}+2 K_{2}+2 K_{3}+K_{4}\right) h \\
I_{i+1} & =I_{i}+\frac{1}{6}\left(G_{1}+2 G_{2}+2 G_{3}+G_{4}\right) h \\
R_{i+1} & =R_{i}+\frac{1}{6}\left(L_{1}+2 L_{2}+2 L_{3}+L_{4}\right) h
\end{aligned}
$$

where:

$$
\begin{aligned}
K_{1} & =f\left(t_{i}, S_{i}\right) \\
K_{2} & =f\left(t_{i}+\frac{1}{2} h, S_{i}+\frac{1}{2} K_{1} h\right) \\
K_{3} & =f\left(t_{i}+\frac{1}{2} h, S_{i}+\frac{1}{2} K_{2} h\right) \\
K_{4} & =f\left(t_{i}+h, S_{i}+K_{3} h\right)
\end{aligned}
$$




$$
\begin{aligned}
G_{1} & =f\left(t_{i}, I_{i}\right) \\
G_{2} & =f\left(t_{i}+\frac{1}{2} h, I_{i}+\frac{1}{2} G_{1} h\right) \\
G_{3} & =f\left(t_{i}+\frac{1}{2} h, I_{i}+\frac{1}{2} G_{2} h\right) \\
G_{4} & =f\left(t_{i}+h, I_{i}+G_{3} h\right) \\
L_{1} & =f\left(t_{i}, R_{i}\right) \\
L_{2} & =f\left(t_{i}+\frac{1}{2} h, R_{i}+\frac{1}{2} L_{1} h\right) \\
L_{3} & =f\left(t_{i}+\frac{1}{2} h, R_{i}+\frac{1}{2} L_{2} h\right) \\
L_{4} & =f\left(t_{i}+h, R_{i}+L_{3} h\right)
\end{aligned}
$$

In order to solve the system of equations 7 to 9 by applying the $4^{\text {th }}$ order Runge-Kutta method, initial conditions are required. The data were obtained from the KRI official website [22] from $1 / 3 / 2020$ to $12 / 8 / 2020$. Taking the total population of KRI as $\mathrm{N}=5,200,000, S=S[0], I=I[0]=4, R[0]=0$. The model mainly depends on two parameters, namely $[\beta]$, the transmission rate, and $[\gamma]$, the recovery rate. Estimating the values of parameters is often a complicated task. Inaccurate parameters for estimating the model are less useful as a predictive tool, although it may still be possible to describe the general behaviour [19]. There are different approaches for estimating the parameters; the first one is to estimate parameters directly based on some experience. Since covid-19 is a new disease, it is difficult to adapt this approach. The second is to compare and fit actual data with a numerical solution by the method of trial and error, with the help of the least square method which has is in this study. The mentioned process of estimating the parameters is called calibrating the model [19].

\section{Results}

The results in Figure 2 show the number of infected individuals that were announced by the KRI, the Ministry of Health, for the period between $1^{\text {st }}$ of March to $12^{\text {th }}$ of August 2020 [22]. The number of confirmed cases started with 4 cases in the beginning of the outbreak in the region. In April, this number declined to its minimum value. While, at the start of May, the cases increased steadily, followed by a rocketed increase in June. Also, the number of infected cases increased from the first of August until preparing this article.

A
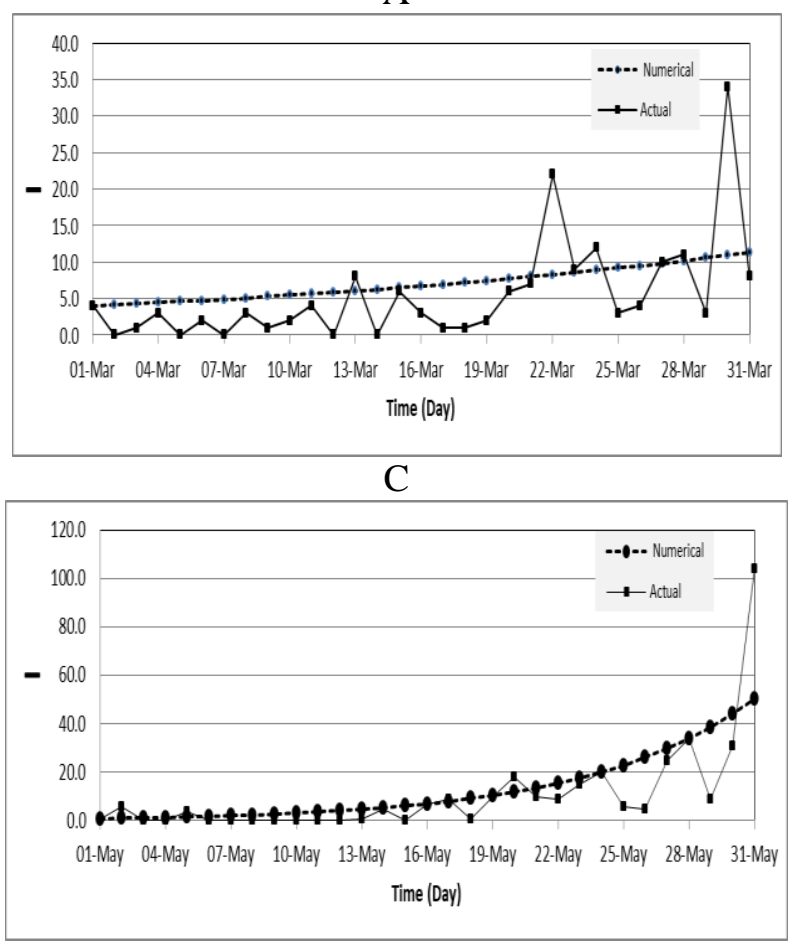

E

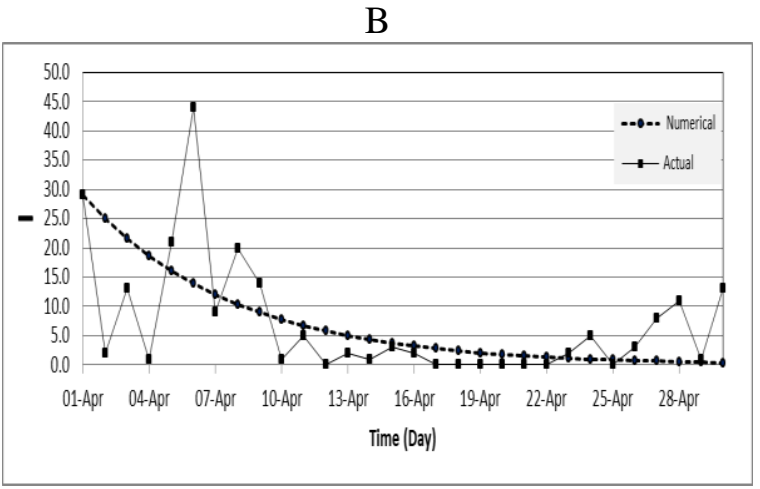

D

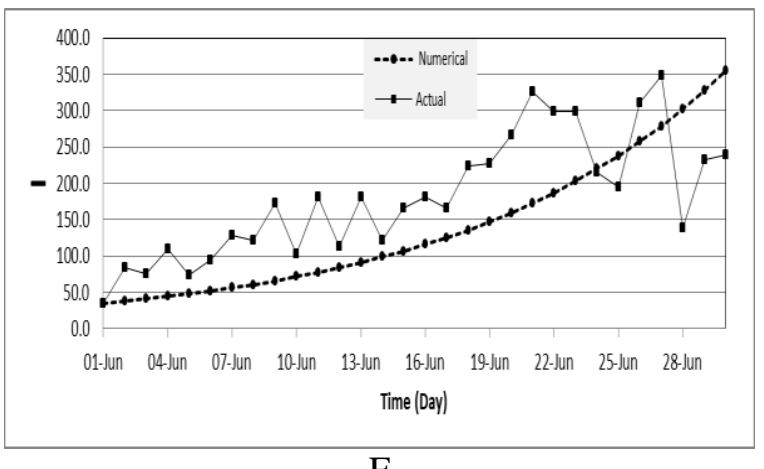

F 


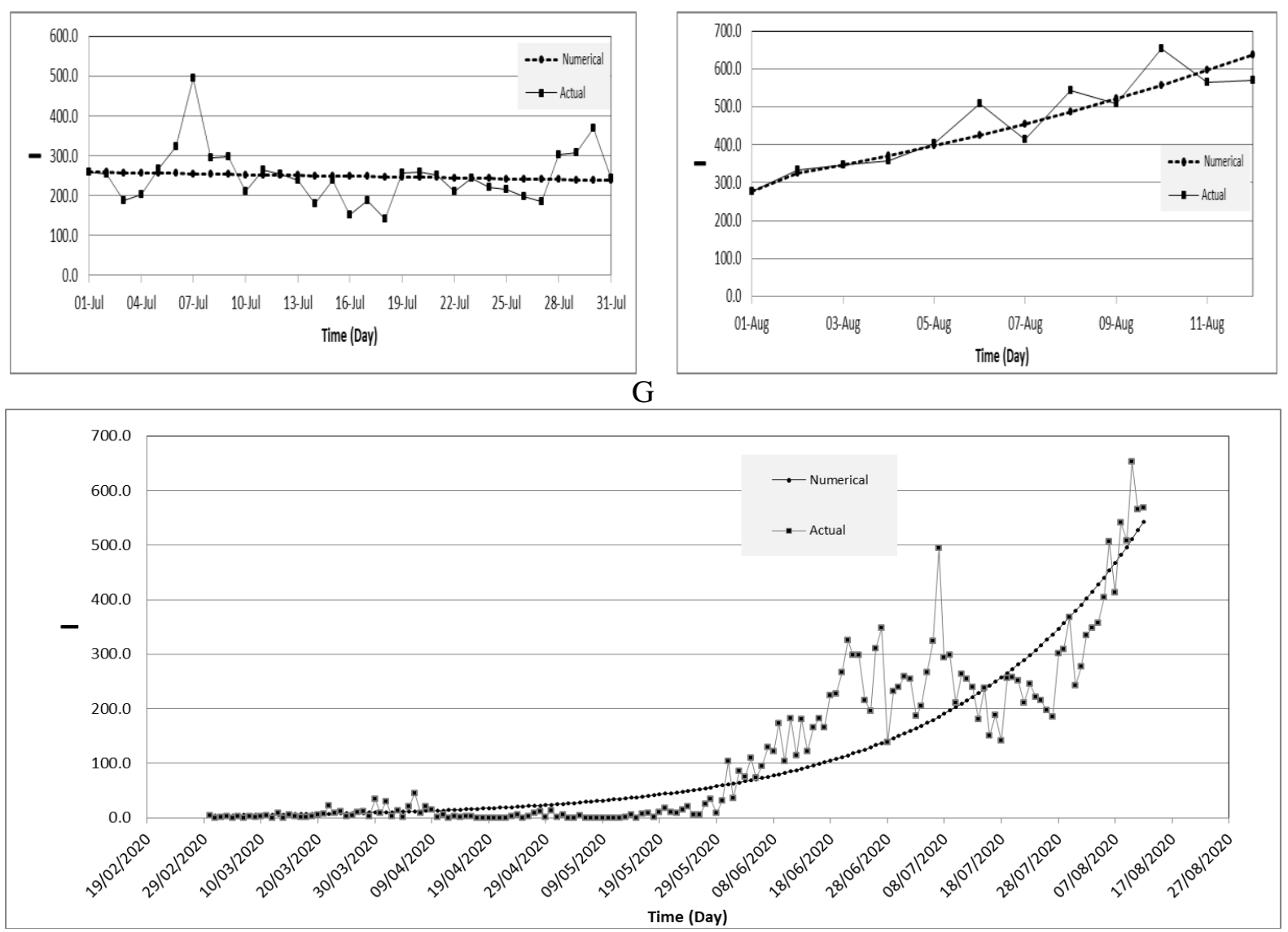

Figure 2-COVID-19 infected cases in KRI for the period from March to August 2020. X axis: Time [days], Y axis: number of infected cases. Monthly infected cases [A-F]: March [A], April [B], May $[C]$, June [D], July [E], August [F]. Total infected cases [G]. Actual monthly infected cases resembling the black line while the red line indicates the numerical results in KRI.

Figure -3 represents the results of $R_{0}$ value for each month as well as the whole period of the outbreak. April experienced the lowest value (0.063). May and June recorded the maximum values of 2.053 and 1.959 , respectively. By using the overall data, the average $R_{0}$ value was estimated to be 1.327 .

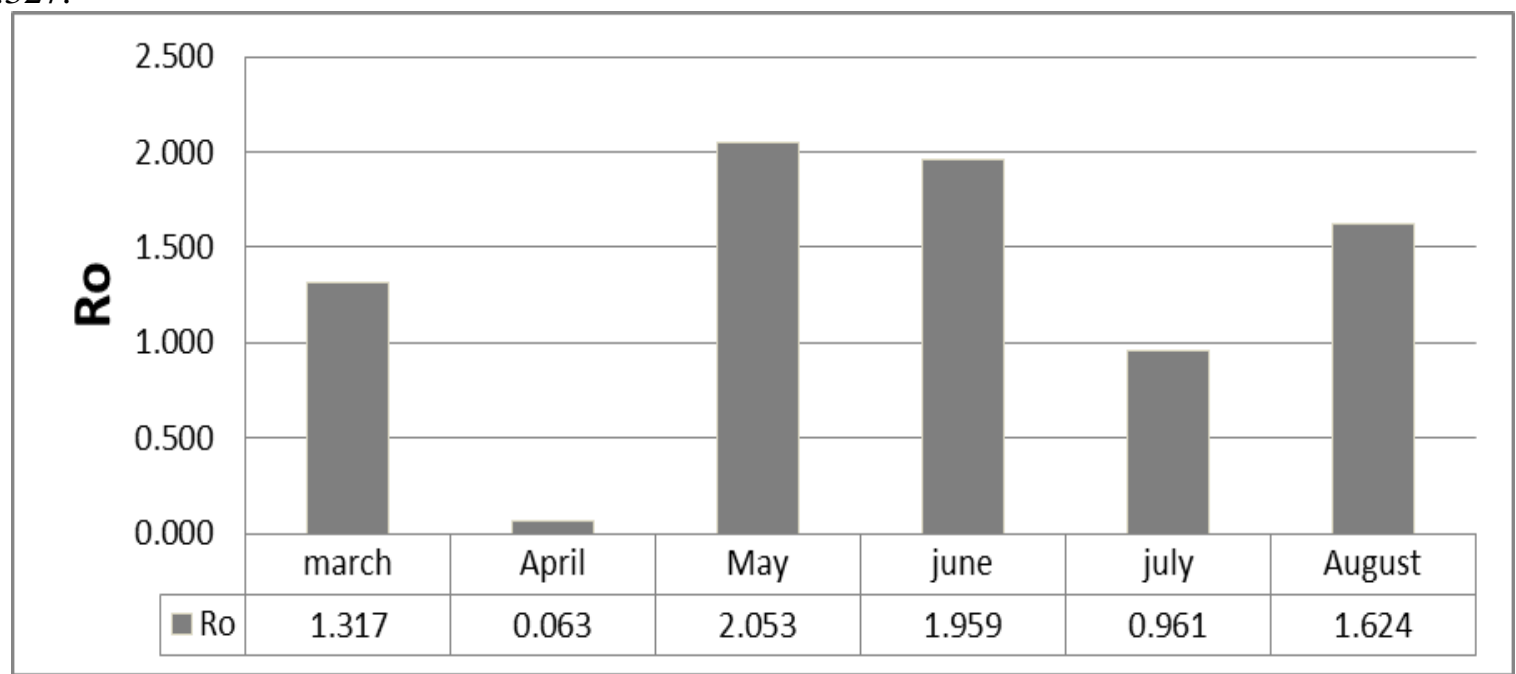

Figure 3-The results of the basic reproduction number $\left[R_{0}\right]$ during the outbreak of COVID-19 in KRI from the beginning of March until $12^{\text {th }}$ of August 2020.

The general SIR model illustrated in figure 4 shows that the predicted infected cases will reach their maximum value of around 540,000 on the $5^{\text {th }}$ of November 2020 . Then, the spread of the disease 
will die out since the number of the susceptible cases will decrease to about 3.2 million and the number of removed individuals will reach approximately to 1.5 million.

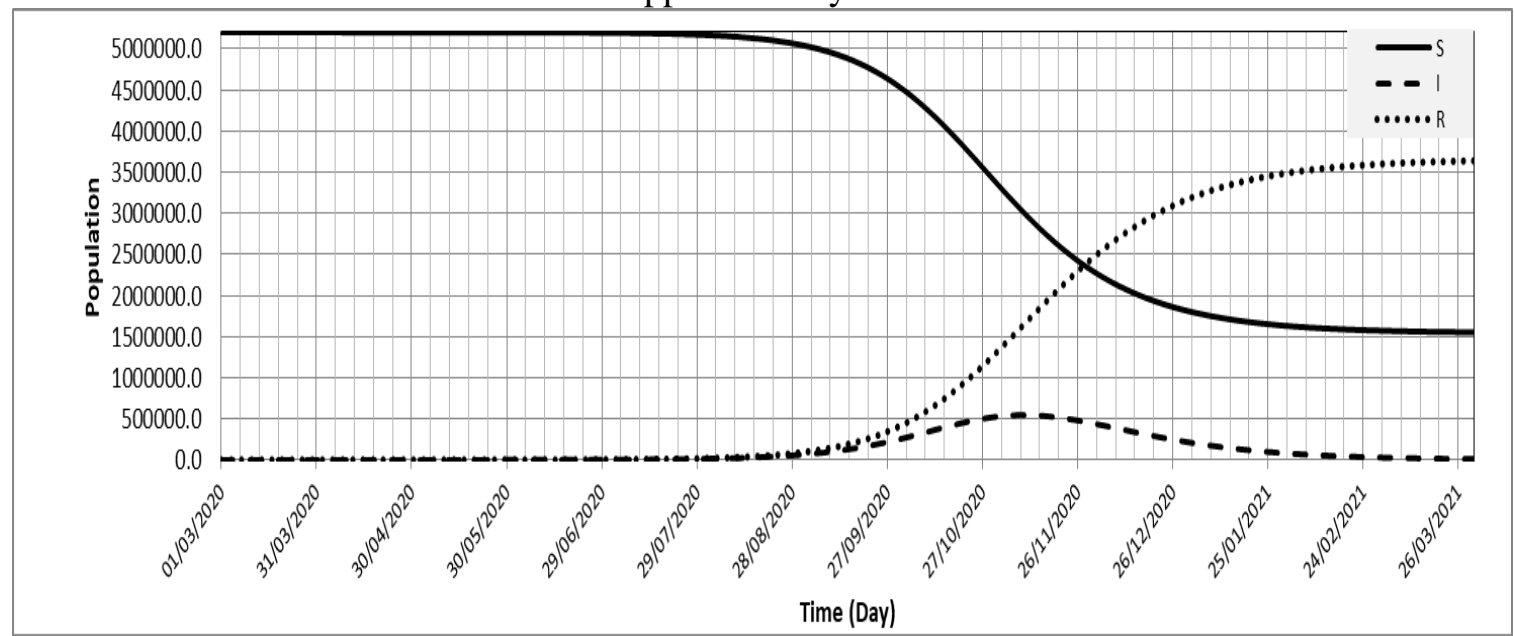

Figure 4-SIR model of prediction for COVID-19 outbreak in KRI [by using the mean of $R_{0}=1.327$ ]. $\mathrm{X}$ axis: Time [days], $\mathrm{Y}$ axis: population number. Blue line [S] resembles susceptible population, red line $[\mathrm{I}]$ represents infected cases, and green line $[\mathrm{R}]$ indicates removed population.

\section{Discussion}

The COVID-19 is spreading with astounding speed and it has severe consequences on health, economic, and social aspects. In the absence of population immunity, effective medicine, and vaccines, the spread of COVID-19 is still expanding exponentially in many countries. Numerical analysis will provide an early warning to the decision-making authority regarding the infected population and a prediction of the time frame for reaching the peak value. Also, it assists authorities to deal with measures amendment in a way fitting the dynamics of the spread of the disease [23, 24].

Numerical modelling has been revealed as a powerful tool to analyse disease behaviour and provide significant information for the authorities to take any necessary actions when needed. From the obtained results, the actual cases were compatible with the numerical analysis, due to the well-fitting characteristics of the used method [17]

In general, most models follow exponential growth. Surprisingly, due to the implementation of several restriction measures, the trend of numerical infected cases in April did not follow the exponential trend. Also, in July, due to high recovery rate, the curve remained nearly in a steady state. Similarly, Maier and Brockmann found that the exponential growth decreases by imposing restriction measures [25], which may lead to a proportional increase of the recovery cases.

Here, we estimated the $R_{0}$ in KRI from the beginning of COVID-19 attack and assessed the SIR model to predict the aftertime of the region in relation to COVID-19 disease. Data released by the Ministry of Health in KRI were used as a source for numerical modelling in this study. Based on these data, the estimated $R_{0}$ values during the time period of six months fluctuated between 0.063 and 2.053. As a consequence of strict restrictions which were implemented by KRI authority in April to contain the outbreak, the lowest estimated value of $R_{0}$ was recorded. While, the sudden and unplanned lifting of measures in May caused a dramatic increase in confirmed cases of COVID-19 [26], which resulted in a highest $R_{0}$. Studies also revealed that travel bans, border closing, lockdown, and social distancing are the most effective containment measures to enhance global readiness needed in response to COVID19 [27]. The average of $R_{0}$ for the time period was around 1.33, which is approximately fit with WHO's declared lower value of 1.4-2.5 [28]. However, other studies estimated the maximum $R_{0}$ value to be around 6.7, with a similar minimum value to that found in our study [29]. $R_{0}$ values strongly are correlated with the implementation of COVID-19 restriction measures, which can be varied among different populations [30].

According to our data analysis, KRI has not reached the peak yet. It is estimated to reach the peak by the $5^{\text {th }}$ of November 2020 . However, the spread of the virus will gradually decrease, since the recovered population will increase and the number of susceptible individuals will decline. On the $26^{\text {th }}$ 
of November 2020, the number of susceptible individuals and recovered individuals will reach the same value.

\section{Conclusions}

In conclusion, the model can predict susceptible populations to SARS-CoV-2 infection along the time until the vaccine is available. The accuracy of the model depends on the quantity of confirmed data available. Therefore, it is important to increase the number of the diagnosis tests for the nonhospitalized population in the region and, as another source of data, use clinical manifestation-based technology of recording.

\section{Conflict of interest}

The authors declare no conflicts of interest.

\section{References}

1. van Doremalen N., Bushmaker T., Morris D. H., Holbrook M. G., Gamble A., Williamson B. N., Tamin A., Harcourt J. L., Thornburg N. J., Gerber S. I. et al. 2020. Aerosol and Surface Stability of SARS-CoV-2 as Compared with SARS-CoV-1. N Engl J Med, 382(16):1564-1567.

2. Xu R., Cui B., Duan X., Zhang P., Zhou X., Yuan Q. Saliva. 2020. potential diagnostic value and transmission of 2019-nCoV. Int J Oral Sci, 12(1):11.

3. Morawska L., Cao J. 2020. Airborne transmission of SARS-CoV-2: The world should face the reality. Environ Int 2020, 139:105730.

4. Li Q., Guan X., Wu P., Wang X., Zhou L., Tong Y., Ren R., Leung K. S. M., Lau E. H. Y., Wong J. Y. et al. 2020. Early Transmission Dynamics in Wuhan, China, of Novel Coronavirus-Infected Pneumonia. N Engl J Med, 382(13):1199-1207.

5. Zhu N., Zhang D., Wang W., Li X., Yang B., Song J., Zhao X., Huang B., Shi W., Lu R. et al. 2019. A Novel Coronavirus from Patients with Pneumonia in China, N Engl J Med 2020, 382(8):727-733.

6. Huang C., Wang Y., Li X., Ren L., Zhao J., Hu Y., Zhang L., Fan G., Xu J., Gu X. et al. 2020. Clinical features of patients infected with 2019 novel coronavirus in Wuhan, China. The Lancet, 395(10223):497-506.

7. Coronavirus disease (COVID-19) pandemic [https://www.who.int/emergencies/diseases/novelcoronavirus-2019]

8. Li Q., Guan X., Wu P., Wang X., Zhou L., Tong Y., Ren R., Leung K. S. M., Lau E. H. Y., Wong J. Y. et al. 2020. Early Transmission Dynamics in Wuhan, China, of Novel Coronavirus-Infected Pneumonia. New England Journal of Medicine, 382(13):1199-1207.

9. Liu T., Hu J., Xiao J., He G., Kang M., Rong Z., Lin L., Zhong H., Huang Q., Deng A. et al. 2020. Time-varying transmission dynamics of Novel Coronavirus Pneumonia in China. bioRxiv:2020.2001.2025.919787.

10. WHO Director-General's opening remarks at the media briefing on COVID-19 - 11 March 2020 [https://www.who.int/dg/speeches/detail/who-director-general-s-opening-remarks-at-the-mediabriefing-on-covid-19---11-march-2020]

11. Giordano G., Blanchini F., Bruno R., Colaneri P., Di Filippo A., Di Matteo A., Colaneri M. 2020. Modelling the COVID-19 epidemic and implementation of population-wide interventions in Italy. Nature Medicine, 26(6):855-860.

12. Kermack W. O., McKendrick A. G. 1927. A contribution to the mathematical theory of epidemics. Proceedings of the royal society of london Series A, Containing papers of a mathematical and physical character, 115(772):700-721.

13. Naji R. K. and Muhseen A. A. 2013. Stability Analysis with Bifurcation of an SVIR Epidemic Model Involving Immigrants. Iraqi Journal of Science. 54(2): 397 -408

14. Al-husseiny, H. F. 2016. Global Stability of an epidemic model with vaccine involving stage structure. Iraqi Journal of Science. 57(4C): 2922 -2931.

15. Shim E., Tariq A., Choi W., Lee Y., Chowell G. 2020. Transmission potential and severity of COVID-19 in South Korea. International Journal of Infectious Diseases, 93:339-344.

16. Zhao S., Chen H. 2020. Modeling the epidemic dynamics and control of COVID-19 outbreak in China. Quant Biol:1-9.

17. COVID-19 dynamics with SIR model [https://www.lewuathe.com/covid-19-dynamics-with-sirmodel.html] 
18. Hasegawa T., Nemoto K. 2017. Efficiency of prompt quarantine measures on a susceptibleinfected-removed model in networks. Physical Review E 2017, 96(2):022311.

19. Barnes B., Fulford G. R. 2014. Mathematical Modelling with Case Studies: Using Maple and MATLAB, vol. 25: CRC Press;.

20. Hamzah F. B. , Lau C., Nazri H., Ligot D., Lee G., Tan C. 2020. CoronaTracker: worldwide COVID-19 outbreak data analysis and prediction. Bull World Health Organ, 1:32.

21. Chapra S. C., Canale R. P. 2010. Numerical methods for engineers: Boston: McGraw-Hill Higher Education.

22. Coronavirus (COVID-19) [https://gov.krd/coronavirus-en/dashboard/]

23. López L., Rodó X. 2020. The end of social confinement and COVID-19 re-emergence risk. Nature Human Behaviour, 4(7):746-755.

24. Cohen M. S., Corey L. 2020. Combination prevention for COVID-19. Science, 368(6491):551551.

25. Maier B. F., Brockmann D. 2020. Effective containment explains subexponential growth in recent confirmed COVID-19 cases in China. Science, 368(6492):742-746.

26. Ali K. M., Tawfeeq H. M., Rostam H. M.2020. COVID-19 Second Spike as an Aftermath of the Sudden Restrictions Ease: Kurdistan Region of Iraq as an Example. Passer Journal:57-62.

27. Gostin L. O., Hodge J. G. 2020. US Emergency Legal Responses to Novel Coronavirus: Balancing Public Health and Civil Liberties. JAMA, 323(12):1131-1132.

28. Statement on the meeting of the International Health Regulations (2005) Emergency Committee regarding the outbreak of novel coronavirus (2019-nCoV) [https://www.who.int/newsroom/detail/23-01-2020-statement-on-the-meeting-of-the-international-health-regulations-(2005)emergency-committee-regarding-the-outbreak-of-novel-coronavirus-(2019-ncov)]

29. Liu Y., Gayle A. A., Wilder-Smith A., Rocklöv J. 2020. The reproductive number of COVID-19 is higher compared to SARS coronavirus. Journal of Travel Medicine, 27(2).

30. Linka K., Peirlinck M., Kuhl E. 2020. The reproduction number of COVID-19 and its correlation with public health interventions. Computational Mechanics. 